\title{
Participation in a free medication program among non-registered permanent residents with severe mental disorders in Bao'an district, Shenzhen, China and its influencing factors
}

Chu-Hong Lu*, Jian-Hu Zhong ${ }^{2}$, Ying-Dong Lv', Jia-Li Luo³, Juan Cheng ${ }^{1}$, Li Qing ${ }^{1}$, Qing Chen ${ }^{1}$ and Cheng-feng Liư

\begin{abstract}
Background: In 2016, the government of Bao'an District, Shenzhen, China launched a free medication program for all non-registered permanent residents with severe mental disorders (SMD) within its jurisdiction, in efforts to reduce the relapse caused by intermittent medication or non-medication. Participation in the program has not been analyzed since its inauguration. This study aimed to evaluate the participation of non-registered permanent residents with SMD in the program from 2016 to 2020 and to explore its influencing factors.

Methods: This is a retrospective cross-sectional study of 3760 non-registered permanent residents with SMD in Bao'an District, Shenzhen, China (response rate: 78.64\%). Data have been obtained from two sources: the Shenzhen Information System for Psychosis in 2020 and the free medication program's management files from 2016 to 2020. We employ descriptive statistics to analyze the participation rate of the free medication program among nonregistered permanent patients. Logistic regression analysis is used to explore the factors affecting the patients' participation in the program.

Results: The participation rate of the free medication program among non-registered permanent patients has shown an upward trend, rising from 28.83\% in 2016 to 58.32\% in 2020. High participation rates have been registered among the following patient subgroups: those aged between 30 and 39 (63.11\%), those with high school/technical secondary school (62.33\%), those from rural areas (61.62\%), those living in poverty (67.79\%), those suffering schizoaffective disorder (72.26\%), those having SMD for less than 5 years (59.89\%), and those with family history of mental illness (71.23\%).Logistics regression analysis shows that age, patient-guardian relationship, place of residence, financial condition, types of disease, duration of illness and family history are the main factors affecting the patients' decision to participate in the free medication program.
\end{abstract}

\footnotetext{
* Correspondence: chuhong688@163.com

'Shenzhen Bao'an Center for Chronic Disease Control, Shenzhen, China

Full list of author information is available at the end of the article
}

(c) The Author(s). 2021 Open Access This article is licensed under a Creative Commons Attribution 4.0 International License, which permits use, sharing, adaptation, distribution and reproduction in any medium or format, as long as you give appropriate credit to the original author(s) and the source, provide a link to the Creative Commons licence, and indicate if changes were made. The images or other third party material in this article are included in the article's Creative Commons licence, unless indicated otherwise in a credit line to the material. If material is not included in the article's Creative Commons licence and your intended use is not permitted by statutory regulation or exceeds the permitted use, you will need to obtain permission directly from the copyright holder. To view a copy of this licence, visit http://creativecommons.org/licenses/by/4.0/ The Creative Commons Public Domain Dedication waiver (http://creativecommons.org/publicdomain/zero/1.0/) applies to the data made available in this article, unless otherwise stated in a credit line to the data. 
Conclusion: The steadily increasing participation rate of the free medication program indicates that the program has been gradually accepted and recognized by non-registered permanent residents with SMD. However, nearly half of the patients have yet to join the program. To further raise the participation rate, special attention should be given to patients who are financially secure, aged below 20, without guardians, intellectually disabled or suffering SMD for over 5 years.

Keywords: Free medication program, Non-registered permanent residents, Severe mental disorders

\section{Background}

According to the Mental Health Law of the People's Republic of China, severe mental disorders (SMD) refer to mental illnesses with serious symptoms that damage the patients' social adaption and other functions and cause their failure to fully understand the reality, realize their own health condition or deal with their personal affairs [1]. SMD include schizophrenia, schizoaffective disorder, delusional disorder, bipolar disorder, psychotic disorder due to epilepsy and intellectual disability with mental disorders. SMD are also found in patients who have conducted behaviors threatening others' safety and those diagnosed with the risk of endangering others [1]. By the end of 2017, China had registered 5.81 million people with SMD [2]. SMD are generally characterized by long course of illness, low cure rate and high recurrence rate. Due to the lack of long-term systematic and standardized treatment, many patients relapse quickly after being treated in the acute stage. Some patients may cause accidents under the influence of SMD with their social functions severely impaired by the illness, which brings a heavy burden to their families and society [3]. Medication is an essential part of the treatment for SMD patients, both in the acute stage and long-term treatment $[4,5]$. According to studies of the medical needs of SMD patients, their most common need is financial aid, including free treatment and medical reimbursement, etc. [6]. In a bid to reduce the recurrence risk for patients due to intermittent medication or non-medication, local health foundations in China, subsidized by the central government, officially launched the treatment project for SMD patients (Project 686) in 2004. Demonstration areas have been established in provincial-level regions across the country to register and evaluate SMD patients, mainly those with schizophrenia. Doctors with township-level health centers and community health centers follow up the patients regularly, check their mental and physical condition, conduct risk assessment, and provid free medicine and hospital treatment for impoverished SMD patients [7]. Since then, local authorities across China have launched free medication programs for registered permanent residents with SMD [8-13]. Previous studies indicated that the implementation of free medication programs can significantly improve the mental condition, social functions, medication adherence and reemployment rate of SMD patients [14-18]. Free medication is of great significance to maintaining social stability and building a harmonious society [19].

Shenzhen is a coastal city in southern China covering a land area of $1997.47 \mathrm{sq}$. km [20]. As a special economic zone, Shenzhen registered a GDP of 2.69 trillion RMB in 2019, ranked third among all cities in the Chinese mainland [20]. The megacity has a population of 13.44 million, including 8.49 million non-registered permanent residents, which account for $63.18 \%$ of the total and are out of proportion to the population of registered permanent residents [20]. Located in the west of Shenzhen, Bao'an District is the largest and most populated among the city's 10 districts [20]. Bao'an has a developed economy and was ranked eighth on the list of China's Top 100 Districts in 2018 [21]. The district has 10 subdistrict offices under its jurisdiction and 2.69 million non-registered permanent residents, which make up $80.53 \%$ of the district's total population [20]. Nonregistered permanent residents paly a vital role in the economic development of China's urban areas [22]. However, most social welfare programs in the urban areas are only available to registered permanent residents, but not to non-registered permanent residents [23-26]. It is the same situation with the free medication programs for SMD patients. In 2006, Bao'an District launched a free medication program for registered permanent residents with SMD. It was not until 2016 that the district introduced a free medication program for non-registered permanent residents with the illness, offering reduction of medication fees (300 RMB/person/ month) and examination fees (800 RMB/person/year). The participation rate of the free medication program among non-registered permanent residents has not been evaluated since it was implemented. Previous relevant studies focused on comparing the situations before and after the implementation of free medication programs, but little academic attention has been paid to analyzing the participation of the programs and characteristics of the participants, especially non-registered permanent residents. This study aims to analyze the participation rate of the free medication program and its impacting 
factors so as to provide key research materials for improving management of and services for non-registered permanent residents with SMD in China's developed areas.

\section{Methods}

\section{Data sources}

This is a retrospective cross-sectional study. Data used in this study have been obtained from two sources: the Shenzhen Information System for Psychosis in 2020 (database of Bao'an District) and the district's management files of the free medication program from 2016 to 2020 , both of which are managed by the professionals with the Bao'an Center for Chronic Disease Control. The professionals conduct regular checks and quality control management of the above two sources to to ensure the data's authenticity, reliability, and accuracy. Data obtained from the Shenzhen Information System for Psychosis include (1) demographic information such as age, gender, education level, marital status, guardian, place of residence and financial condition; (2) clinical information such as type of disease, duration of illness and family history of mental illness. Information of the participants of Bao'an District's free medication program, including their ID card number and date of application for the program, has been obtained from the program's management files from 2016 to 2020.

\section{Participants}

Research subjects of this study are SMD patients in Bao'an District who have been diagnosed by medical institutions and registered in the Shenzhen Information System for Psychosis before December 31, 2020, meet the standard of non-registered permanent residents, and receive regular follow-up management by local communities. Patients who are deceased, losing contact in, unmanaged or under temporary assistance as well as 749 questionnaires with incomplete information have been excluded from this study. The subjects of the study include 3760 non-registered permanent residents with SMD. Figure 1, a flow diagram, describes how the subjects are recruited and excluded. All non-registered permanent residents with SMD, who are included in the Shenzhen Information System and receive regular follow-up management by local communities, can apply for the free medication program in Bao'an District. Doctors with the community health centers are required to inform all patients of the program during follow-up visits of the patients (face to face, by WeChat or phone calls, etc.) and receive clear replies from the patients about whether they will participate in the program. In addition, the doctors are required to assist the patients in application if they agree to participate. This study was approved by the Bao'an Center for Chronic Disease
Control (Shenzhen, China). All methods were performed in accordance with the relevant guidelines and regulations.

\section{Description of related definitions}

Non-registered permanent residents: according to China's current demographic system and demographic monitoring methods issued by the Shenzhen municipal government, since 2006, non-registered permanent residents in Shenzhen refer to people who have lived in the city for over 6 months but do not have Hukou, or household registration status. Impoverished residents in Shenzhen refer to people living on government allowances whose monthly income is less than 1.5 times the minimum living standard in Shenzhen (1740 yuan). According to China's National Basic Public Health Service Standard (third edition), guardian of SMD patients is a person who exercises the duties of guardianship according to law. Medication adherence is divided into three categories:regular medication, intermittent medication and non-medication. Regular medication means the patients take medicines according to doctor's advice and does not stop, reduce, or increase the dosage of medicines by themselves. Intermittent medication means the patients do not follow doctor's advice to take medicines or reduce the frequency and quantity of medication by themselves. Non-medication means that the patients do not take any of the medicines prescribed by doctors or that the doctors think the patients have recovered with no need for medication.

\section{Statistical analysis}

Statistical analysis is performed with SPSS 26.0. Descriptive statistics are used to analyze the quantity and ratio, and chi-square test is employed to compare the difference of demographic and clinical variables between different groups among non-registered permanent residents with SMD. Candidate variables with a $P$ value $<0.2$ on univariate analysis are included in multivariate logistic regression to evaluate factors associated with the participation rate of the free medication program among non-registered permanent residents with SMD. $P$ values $<0.05$ are considered statistically significant.

\section{Results \\ Participation rate of free medication program in 2016- 2020}

By the end of 2020, there were 7421 SMD patients in Bao'an District, Shenzhen. Among them, 4953 were non-registered permanent residents, accounting for $66.74 \%$ of the total. Of the non-registered permanent residents with SMD, 172 were excluded from this study because they had deceased before the research started. After the recruitment and exclusion processes (Fig. 1), a 


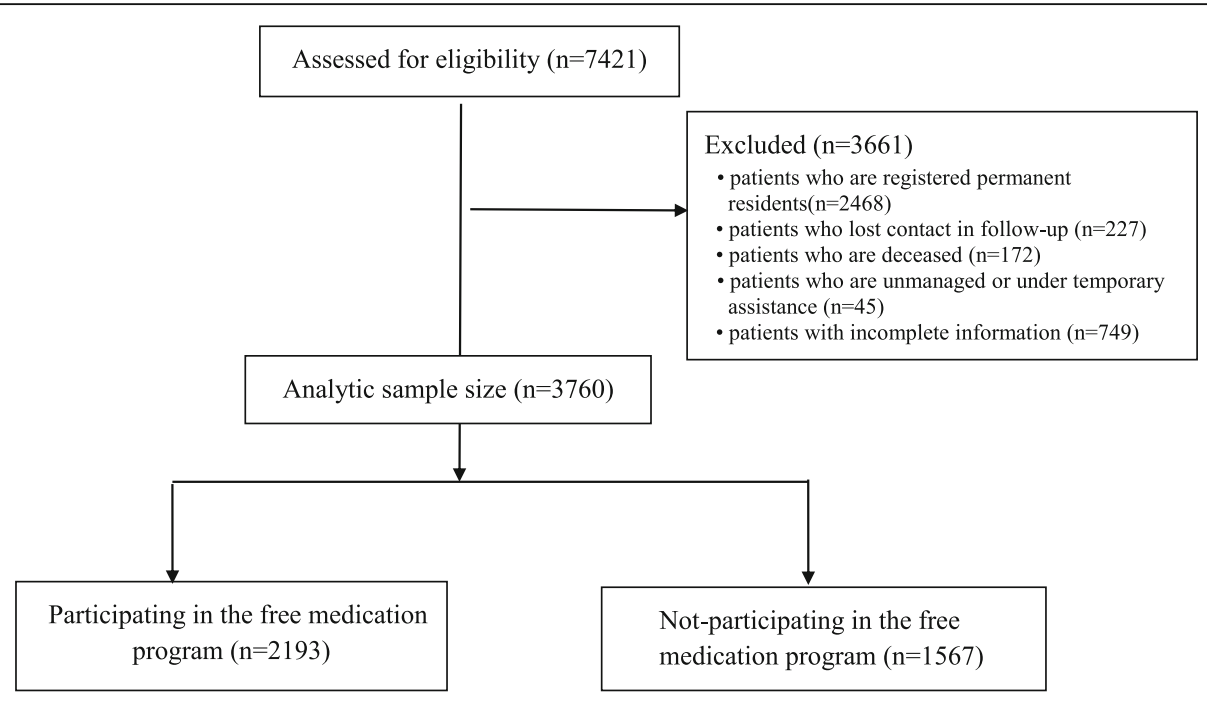

Fig. 1 Flowchart illustrating the patient recruitment and exclusion processes in the study of the free medication program

total of 3760 individuals (with complete data) were recruited from the 4781 eligible non-registered permanent residents with SMD, and the overall response rate was 78.64\%.Participation in the free medication program among non-registered permanent residents with SMD from 2016 to 2020 is presented in Table 1. From 2016 to 2020 , the participation rate of the free medication program among non-registered permanent residents with SMD in Bao'an District, Shenzhen, is 28.83, 40.47, 43.73, 51.58 and $58.32 \%$, respectively, and the participation rate shows an upward trend (Chi-square Trend $=501.357$, $P<0.001)$.

\section{Psychotropic drug and medication adherence of non- registered permanent residents with SMD}

From 2016 to 2020, the cost of antipsychotic drugs for 2193 non-registered permanent residents with SMD in Bao'an District totaled 8.76 million RMB. The per capita cost was 3995.94 RMB. In 2020, olanzapine was the most frequently used antipsychotic drug among participants in the free medication program, followed by valproate, risperidone, aripiprazole, quetiapine, clozapine, amisulpride, lithium carbonate and benzodiazepines.
Olanzapine was the most frequently used in intellectually disabled patients with mental disorders, followed by valproate, risperidone, amisulpride, aripiprazole, quetiapine, oxcarbazepine, clozapine and benzodiazepines. Figure 2 shows the medication adherence of patients participating in the free medication program and those not participating. $92.20 \%$ of the patients participating in the program are able to take regular medication, while only $53.41 \%$ of the non-participating patients take the drugs regularly. 3.10 and $4.70 \%$ of the patients participating in the program show intermittent medication and non-medication, respectively, compared with 5.36 and $41.23 \%$ in the non-participating patients.

\section{Demographic and clinical characteristics}

The socio-demographic and clinical characteristics of the participating and non- participating patients are shown in Table 2. The study covers 3760 patients, of which 2193(58.32\%) have participated in the free medication program and 1567 (41.68\%) have not. The 30-39 age group registers the highest participation rate (63.11\%, $P<0.001$ ), while the under-20 age group posts the lowest participation rate $(30.15 \%, P<0.001)$. In terms

Table 1 Participation in the free medication program among non-registered permanent residents with SMD from 2016 to 2020

\begin{tabular}{|c|c|c|c|c|c|c|}
\hline \multirow[t]{2}{*}{ Year } & \multicolumn{2}{|c|}{ Participating } & \multicolumn{2}{|c|}{ Non-participating } & \multirow{2}{*}{$\begin{array}{l}\text { Chi-square } \\
\text { Trend }\end{array}$} & \multirow[t]{2}{*}{$P$ value } \\
\hline & $\mathrm{N}$ & $\%$ & $\mathrm{~N}$ & $\%$ & & \\
\hline 2016 & 517 & 28.83 & 1276 & 71.17 & 501.357 & $<0.001$ \\
\hline 2017 & 955 & 40.47 & 1405 & 59.53 & & \\
\hline 2018 & 1251 & 43.73 & 1610 & 56.27 & & \\
\hline 2019 & 1750 & 51.58 & 1643 & 48.42 & & \\
\hline 2020 & 2193 & 58.32 & 1567 & 41.68 & & \\
\hline
\end{tabular}




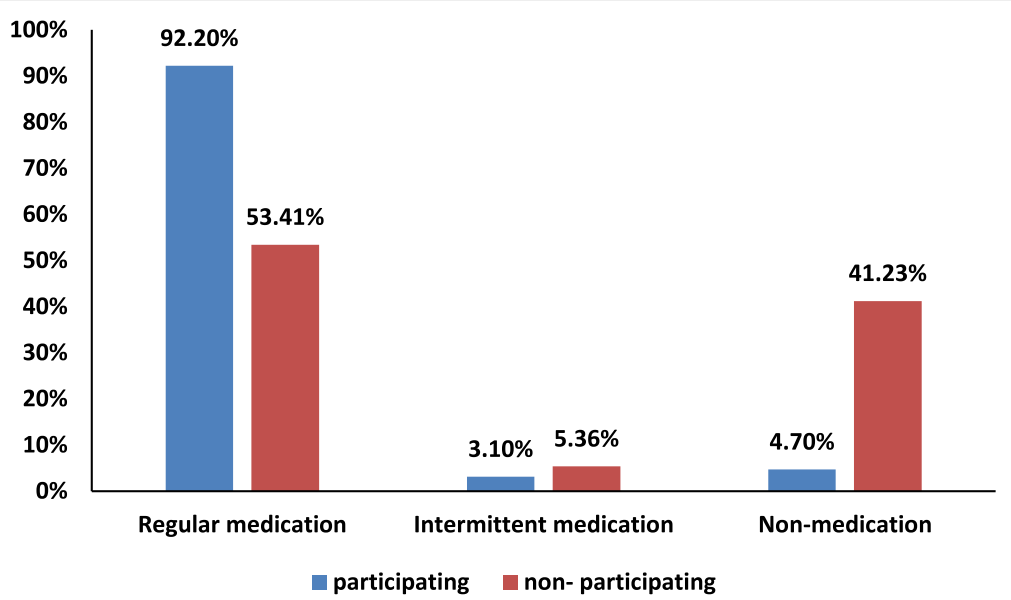

Fig. 2 Medication adherence of non-registered permanent residents with SMD participating and not participating in free medication program

of education level, patients with junior high school, and high school or technical secondary school diplomas show relatively high participation rates $(62.24$ and $62.33 \%$, respectively), while illiterate or semiliterate patients record the lowest participation rate $(39.38 \%, P<$ $0.001)$. Married and divorced patients register relatively high participation rates (60.51 and $61.15 \%$, respectively), and widowed patients show the lowest participation rate (48.00\%, $P<0.05)$. Patients whose guardian is a spouse have the highest participation rate $(62.74 \%, P<0.001)$. The participation rate of patients living in rural areas is higher than that of patients living in urban areas or foreign countries $(61.62 \%, P<0.001)$. The impoverished patients show higher participation rate than the financially secure ones $(67.79 \%, P<0.001)$. Patients with schizoaffective disorder have the highest participation rate $(72.26 \%$, $P<0.001)$ among all types of mental illness. Patients suffering SMD for less than 5 years show the highest participation rate $(59.89 \%, P<0.05)$ than those with other duration of illness. Patients with family history of mental illness record higher participation rate than those without family history $(71.23 \%, P<0.05)$.

\section{Factors influencing participation in free medication program}

The factors affecting the participation in the free medication program are listed in Table 3. Logistic regression analysis shows that using the under-20 age group as a reference group, the 30-39 age group's participation rate is 2.66 times that of the reference group ( $\mathrm{OR}=2.66,95 \%$ $\mathrm{CI}=1.81-3.90$ ), and the under-20 age group has the lowest participation rate. However, the patients' education level and marital status are not associated with their participation rate. Using patients without guardians as a reference group, the participation rate of the patients with their parents as guardians is 3.64 times that of the reference group $(\mathrm{OR}=3.64,95 \% \mathrm{CI}=2.49-5.32)$. The participation rate of patients living in rural areas is 1.51 times that of those residing in urban areas or foreign countries $(\mathrm{OR}=1.51,95 \% \mathrm{CI}=1.30-1.77)$. The participation rate of impoverished patients is 1.63 times that of financially secure ones $(\mathrm{OR}=1.63,95 \% \mathrm{CI}=1.36-1.95)$. Using patients with schizophrenia as a reference group, patients with schizoaffective disorder have higher participation rate $(\mathrm{OR}=1.56,95 \% \mathrm{CI}=1.06-2.31)$, while those with bipolar disorder and with intellectual disability show lower participation rates $(\mathrm{OR}=0.80,95 \% \mathrm{CI}=$ 0.67-0.96; $\mathrm{OR}=0.27,95 \% \mathrm{CI}=0.18-0.41)$. Patients suffering SMD for 5 to 9 years have lower participation rate, only $73 \%$ of the participation rate of those suffering the illness for less than 5 years $(\mathrm{OR}=0.73,95 \% \mathrm{CI}=0.62-$ $0.85)$. The participation rate of patients with family history of mental illness is 1.84 times that of those without family history $(\mathrm{OR}=1.84,95 \% \mathrm{CI}=1.08-3.14)$.

\section{Discussion}

This study is the first research into the participation of the free medication program in Bao'an District, Shenzhen, among non-registered permanent residents with SMD since the program was launched in 2016. As far as we know, this is also the first study in China to focus on the participation of non-registered permanent residents with SMD in the free medication program. Compared to the participation rate of registered permanent residents with SMD in Bao'an District in 2020(34.74\%, not listed in the table), the participation rate $(58.32 \%)$ of nonregistered permanent patients is higher, according to this study. Non-registered permanent patients usually face more financial challenges than registered permanent patients and are more inclined to obtain subsidies to relieve their family of economic burden [10]. 
Table 2 Socio-demographic and clinical characteristics of the participating and non- participating patients

\begin{tabular}{|c|c|c|c|c|c|c|c|c|}
\hline \multirow[t]{2}{*}{ Variable name } & \multirow[t]{2}{*}{$\mathrm{N}=$} & \multirow[t]{2}{*}{$\%$} & \multicolumn{2}{|c|}{ Participating ( $n=2193)$} & \multicolumn{2}{|c|}{ Non- participating $(n=1567)$} & \multirow{2}{*}{$\begin{array}{l}\text { Chi- } \\
\text { square }\end{array}$} & \multirow{2}{*}{$\begin{array}{l}P \\
\text { value }\end{array}$} \\
\hline & & & $\mathbf{N}$ & $\%$ & $\mathbf{N}$ & $\%$ & & \\
\hline Gender & & & & & & & 2.474 & 0.116 \\
\hline Male & 1805 & 48.01 & 1029 & 57.01 & 776 & 42.99 & & \\
\hline Female & 1955 & 51.99 & 1164 & 59.54 & 791 & 40.46 & & \\
\hline Age (Years) & & & & & & & 98.605 & $<0.001$ \\
\hline$<20$ & 262 & 6.97 & 79 & 30.15 & 183 & 69.85 & & \\
\hline 20 to 29 & 834 & 22.18 & 505 & 60.55 & 329 & 39.45 & & \\
\hline 30 to 39 & 1171 & 31.14 & 739 & 63.11 & 432 & 36.89 & & \\
\hline 40 to 49 & 626 & 16.65 & 370 & 59.11 & 256 & 40.89 & & \\
\hline 50 to 59 & 501 & 13.32 & 290 & 57.88 & 211 & 42.12 & & \\
\hline$\geq 60$ & 366 & 9.73 & 210 & 57.38 & 156 & 42.62 & & \\
\hline Education level & & & & & & & 63.821 & $<0.001$ \\
\hline Illiteracy/semiliterate & 320 & 8.51 & 126 & 39.38 & 194 & 60.63 & & \\
\hline Primary school & 659 & 17.53 & 367 & 55.69 & 292 & 44.31 & & \\
\hline Junior high school & 1462 & 38.88 & 910 & 62.24 & 552 & 37.76 & & \\
\hline High school/technical secondary school & 738 & 19.63 & 460 & 62.33 & 278 & 37.67 & & \\
\hline College degree and above & 581 & 15.45 & 330 & 56.80 & 251 & 43.20 & & \\
\hline Marital status & & & & & & & 11.909 & 0.008 \\
\hline Married & 2036 & 54.15 & 1232 & 60.51 & 804 & 39.49 & & \\
\hline Unmarried & 1517 & 40.35 & 841 & 55.44 & 676 & 44.56 & & \\
\hline Divorced & 157 & 4.18 & 96 & 61.15 & 61 & 38.85 & & \\
\hline Widowed & 50 & 1.33 & 24 & 48.00 & 26 & 52.00 & & \\
\hline Guardian & & & & & & & 50.817 & $<0.001$ \\
\hline Spouse & 1205 & 32.05 & 756 & 62.74 & 449 & 37.26 & & \\
\hline Parents & 1218 & 32.39 & 702 & 57.64 & 516 & 42.36 & & \\
\hline Children & 481 & 12.79 & 290 & 60.29 & 191 & 39.71 & & \\
\hline Relative & 582 & 15.48 & 333 & 57.22 & 249 & 42.78 & & \\
\hline Friends and others & 121 & 3.22 & 59 & 48.76 & 62 & 51.24 & & \\
\hline None & 153 & 4.07 & 53 & 34.64 & 100 & 65.36 & & \\
\hline Residence & & & & & & & 43.344 & $<0.001$ \\
\hline Urban /Foreign & 1048 & 27.79 & 522 & 49.81 & 526 & 50.19 & & \\
\hline Rural & 2712 & 72.21 & 1671 & 61.62 & 1041 & 38.38 & & \\
\hline Financial condition & & & & & & & 34.073 & $<0.001$ \\
\hline Non-poverty & 3018 & 80.27 & 1690 & 56.00 & 1328 & 44.00 & & \\
\hline Poverty & 742 & 19.73 & 503 & 67.79 & 239 & 32.21 & & \\
\hline Types of disease & & & & & & & 154.521 & $<0.001$ \\
\hline Schizophrenia & 2351 & 62.53 & 1459 & 62.06 & 892 & 37.94 & & \\
\hline Schizoaffective disorder & 137 & 3.64 & 99 & 72.26 & 38 & 27.74 & & \\
\hline Paranoid disorder & 34 & 0.90 & 17 & 50.00 & 17 & 50.00 & & \\
\hline Bipolar disorder & 740 & 19.68 & 414 & 55.95 & 326 & 44.05 & & \\
\hline Epileptic mental disorder & 79 & 2.10 & 51 & 64.56 & 28 & 35.44 & & \\
\hline Intellectual disability with mental disorders & 249 & 6.62 & 58 & 23.29 & 191 & 76.71 & & \\
\hline Other mental disorders & 170 & 4.52 & 95 & 55.88 & 75 & 44.12 & & \\
\hline Duration of illness (year) & & & & & & & 6.079 & 0.048 \\
\hline
\end{tabular}


Table 2 Socio-demographic and clinical characteristics of the participating and non- participating patients (Continued)

\begin{tabular}{|c|c|c|c|c|c|c|c|c|}
\hline \multirow[t]{2}{*}{ Variable name } & \multirow[t]{2}{*}{$N=$} & \multirow[t]{2}{*}{$\%$} & \multicolumn{2}{|c|}{ Participating ( $n=2193)$} & \multicolumn{2}{|c|}{ Non- participating $(n=1567)$} & \multirow{2}{*}{$\begin{array}{l}\text { Chi- } \\
\text { square }\end{array}$} & \multirow{2}{*}{$\begin{array}{l}P \\
\text { value }\end{array}$} \\
\hline & & & $\mathrm{N}$ & $\%$ & $\mathrm{~N}$ & $\%$ & & \\
\hline$<5$ & 1790 & 47.61 & 1072 & 59.89 & 718 & 40.11 & & \\
\hline 5 to 9 & 1241 & 33.01 & 689 & 55.52 & 552 & 44.48 & & \\
\hline$\geq 10$ & 729 & 19.39 & 432 & 59.26 & 297 & 40.74 & & \\
\hline Family history of mental illness & & & & & & & 5.103 & 0.024 \\
\hline Yes & 73 & 1.94 & 52 & 71.23 & 21 & 28.77 & & \\
\hline No & 3687 & 98.06 & 2141 & 58.07 & 1546 & 41.93 & & \\
\hline
\end{tabular}

This study shows that although Bao'an District, Shenzhen, has higher medicine subsidies than Dahongmen District,Beijing [9], the participation rate of nonregistered permanent patients in Bao'an in 2017 (40.47\%) was still lower than that of registered permanent patients in Beijing in the same year (49\%) [10], and the participation rate of non-registered permanent patients in Bao'an in 2018 (43.73\%) was lower than that of registered permanent patients in Dahongmen in the same year (67.82\%). The participation rate of nonregistered permanent residents with schizophrenia in Bao'an stood at $62.06 \%$ in 2020 , lower than that of registered permanent residents with the same disease in remote communities in southwest China's Yunnan Province in 2013 (70.35\%) [13]. In 2019, Bao'an District covers an area of 396.61 sq. $\mathrm{km}$ and has a permanent population of 3.34 million. However, due to the shortage of mental health resources, only one hospital in the district offered psychiatric outpatient services and undertook the free medication program. In order to improve the patients' medication rate and optimize the program, Bao'an established clinical psychology departments in 6 hospitals in 2019, and each department is staffed with full-time psychiatrists by the end of 2020. The participation rate of the free medication program has increased steadily year by year, indicating that the program has been gradually accepted and recognized by nonregistered permanent residents with SMD. However, nearly half of the patients have yet to join the program. This is an interesting discovery that may be related to the patients' stigma consciousness, deficient awareness of the importance of medication [10, 13, 27], lack of access to metal health resources and medical care, and complicated application process in Bao'an District [12, $28,29]$ This aspect can be further investigated in future studies to find out why some non-registered permanent residents have not participated in the free medication program.

The influencing factors discussed in this study are more focused on patient-related factors, including gender, age, education level, marital status, relationship with guardian, place of residence, financial condition, types of disease, duration of illness and family history. This study shows that patients aged below 20 have the lowest participation rate, while those aged between 30 and 39 have the highest participation rate. This finding is inconsistent with the research result of the free medication program among registered permanent patients in Dahongmen District, Beijing, which shows that age has no influence on the participation rate [9]. It is also in contradiction with the result of the free medication program among registered permanent patients in remote communities in Yunnan Province, which shows a negative correlation between age and participation rate [13]. One possible explanation for the inconsistencies is that among the patients aged below 20 in Bao'an, 59.54\% are intellectually disabled patients with metal disorders, and patients with this disease has the lowest participation rate (only $12.18 \%$ ). Compared to patients without guardians, those who have their parents, children, spouses, relatives and friends as guardians are more inclined to participate in the free medication program, especially if their parents are their guardians. One possible reason is that parents pay more attention to patients and are more willing to take care of patients with all their heart [30]. Poverty is a factor affecting the medication adherence of SMD patients [30, 31]. This study shows that impoverished patients are more likely to participate in the free medication program, which is consistent with previous research on the free medication program for registered permanent patients [10, 30-32]. The free medication program can reduce economic pressures for families, so patients from financially challenged families are more likely to participate in the program [10]. The study of Wang Xun et al. shows that the medication adherence of rural patients is lower than that of urban patients after discharge from hospitals [32]. In contrast, this study shows that rural patients are more inclined to participate in the free medication program than urban and foreign patients, and patients with family history of mental illness are more inclined to participate. This may be related to the patients' financial condition. In addition, this 
Table 3 Factors influencing participation in the free medication program by logistic regression analyses

\begin{tabular}{|c|c|c|c|c|c|c|c|}
\hline Variable name & B & S.E. & Wald & OR & $95 \% \mathrm{Cl}$ & & $p$-value \\
\hline \multicolumn{8}{|l|}{ Gender } \\
\hline Female & & & & 1 & & & \\
\hline Male & -0.02 & 0.08 & 0.04 & 0.99 & 0.85 & 1.14 & 0.838 \\
\hline \multicolumn{8}{|l|}{ Age (years) } \\
\hline$<20$ & & & & 1 & - & - & - \\
\hline 20 to 29 & 0.78 & 0.18 & 18.18 & 2.18 & 1.52 & 3.12 & 0.001 \\
\hline 30 to 39 & 0.98 & 0.20 & 25.09 & 2.66 & 1.81 & 3.90 & $<0.001$ \\
\hline 40 to 49 & 0.80 & 0.22 & 13.54 & 2.22 & 1.45 & 3.40 & $<0.001$ \\
\hline 50 to 59 & 0.72 & 0.23 & 9.65 & 2.05 & 1.30 & 3.21 & 0.002 \\
\hline$\geq 60$ & 0.72 & 0.26 & 7.71 & 2.06 & 1.24 & 3.42 & 0.005 \\
\hline \multicolumn{8}{|l|}{ Educational level } \\
\hline Illiteracy/semiliterate & & & & 1 & & & \\
\hline Primary school & 0.09 & 0.17 & 0.27 & 1.09 & 0.79 & 1.51 & 0.601 \\
\hline Junior high school & 0.22 & 0.17 & 1.77 & 1.25 & 0.90 & 1.74 & 0.183 \\
\hline High school or technical secondary school & 0.34 & 0.18 & 3.49 & 1.40 & 0.98 & 1.99 & 0.062 \\
\hline College degree and above & 0.13 & 0.19 & 0.48 & 1.14 & 0.79 & 1.65 & 0.490 \\
\hline \multicolumn{8}{|l|}{ Marital status } \\
\hline Unmarried & & & & 1 & & & \\
\hline Married & -0.05 & 0.13 & 0.18 & 0.95 & 0.74 & 1.22 & 0.676 \\
\hline Divorced & 0.12 & 0.19 & 0.37 & 1.12 & 0.77 & 1.64 & 0.546 \\
\hline Widowed & -0.38 & 0.33 & 1.31 & 0.69 & 0.36 & 1.31 & 0.252 \\
\hline \multicolumn{8}{|l|}{ Guardian } \\
\hline None & & & & 1 & & & \\
\hline Friends and others & 0.66 & 0.26 & 6.47 & 1.93 & 1.16 & 3.19 & 0.011 \\
\hline Relative & 0.91 & 0.20 & 21.71 & 2.49 & 1.70 & 3.66 & $<0.001$ \\
\hline Parents & 1.29 & 0.19 & 44.26 & 3.64 & 2.49 & 5.32 & $<0.001$ \\
\hline Children & 1.29 & 0.23 & 31.04 & 3.63 & 2.31 & 5.71 & $<0.001$ \\
\hline Mate & 1.17 & 0.20 & 36.38 & 3.23 & 2.21 & 4.73 & $<0.001$ \\
\hline \multicolumn{8}{|l|}{ Residence } \\
\hline Urban / Foreign & & & & 1 & & & \\
\hline Rural & 0.41 & 0.08 & 27.18 & 1.51 & 1.30 & 1.77 & $<0.001$ \\
\hline \multicolumn{8}{|l|}{ Financial condition } \\
\hline Non-poverty & & & & 1 & & & \\
\hline Poverty & 0.49 & 0.09 & 28.32 & 1.63 & 1.36 & 1.95 & $<0.001$ \\
\hline \multicolumn{8}{|l|}{ Types of disease } \\
\hline Schizophrenia & & & & 1 & & & \\
\hline Schizoaffective disorder & 0.45 & 0.20 & 4.95 & 1.56 & 1.06 & 2.31 & 0.026 \\
\hline Paranoid disorder & -0.50 & 0.35 & 1.97 & 0.61 & 0.304 & 1.22 & 0.160 \\
\hline Bipolar disorder & -0.22 & 0.09 & 5.88 & 0.80 & 0.67 & 0.96 & 0.015 \\
\hline Epileptic mental disorder & 0.08 & 0.25 & 0.11 & 1.08 & 0.67 & 1.77 & 0.746 \\
\hline Intellectual disability with mental disorders & -1.30 & 0.21 & 39.20 & 0.27 & 0.18 & 0.41 & $<0.001$ \\
\hline Other mental disorders & -0.36 & 0.17 & 4.67 & 0.70 & 0.51 & 0.97 & 0.031 \\
\hline
\end{tabular}

Duration of illness (year) 
Table 3 Factors influencing participation in the free medication program by logistic regression analyses (Continued)

\begin{tabular}{|c|c|c|c|c|c|c|c|}
\hline \multirow{2}{*}{$\frac{\text { Variable name }}{5 \text { to } 9}$} & \multirow{2}{*}{$\begin{array}{l}\text { B } \\
-0.32\end{array}$} & \multirow{2}{*}{$\begin{array}{l}\text { S.E. } \\
0.08\end{array}$} & \multirow{2}{*}{$\begin{array}{l}\text { Wald } \\
15.59\end{array}$} & \multirow{2}{*}{$\frac{\text { OR }}{0.73}$} & \multicolumn{2}{|c|}{$95 \% \mathrm{Cl}$} & \multirow{2}{*}{$\frac{p \text {-value }}{<0.001}$} \\
\hline & & & & & 0.62 & 0.85 & \\
\hline$\geq 10$ & -0.18 & 0.10 & 3.48 & 0.83 & 0.69 & 1.01 & 0.062 \\
\hline \multicolumn{8}{|c|}{ Family history of mental illness } \\
\hline No & & & & 1 & & & \\
\hline Yes & 0.61 & 0.27 & 4.96 & 1.84 & 1.08 & 3.14 & 0.026 \\
\hline
\end{tabular}

study shows that education level and marital status have no impact on the participation rate of the free medication program in Bao'an, which is in line with the research result of the free medication program among registered permanent patients in Dahongmen [9].

This study shows that among all types of mental illness, intellectually disabled patients with mental disorders have the lowest participation rate, only $27 \%$ of that of patients with schizophrenia. This finding is inconsistent with the research result of the free medication program among unemployed, impoverished registered permanent residents with metal illness in Shanghai, which shows that patients with schizoaffective disorder have the lowest participation rate [12]. The low participation rate among intellectually disabled patients with mental disorders may be related to the low medication rate for this disease [27, 33]. These patient were usually diagnosed with intellectual disability at a very young age, which caused their family to give up treatment [27]. The low participation rate of these patients may also be related to the low education level of their family members, which lead to the latter's failure to fully perform their role as guardians [33].

The participation rate of patients suffering SMD for 5 to 9 years is lower than that of patients suffering the disease for less than 5 years. This may be because patients with chronic diseases usually lack confidence in medical treatment and suffer from symptoms such as indolence and withdrawal $[34,35]$.

\section{Limitations}

The free medication program in Bao'an District, Shenzhen, China covers all non-registered permanent residents with SMD within the district. It only applies to non-registered permanent residents (registered permanent patients are not applicable), making it difficult to evaluate the influencing factors with rigorous designs such as randomized controlled or comparative studies. The subjects of this study are limited to non-registered permanent residents with SMD in Bao'an District (which make up nearly $70 \%$ of SMD patients in the district), thus affecting the extrapolation of the research results. The data used in this study only contain the patients' demographic and clinical characteristics, so the influencing factors discussed in the study focus more on patient-related factors. Lack of investigation into the specific reasons for the patients' non-participation, including personal/family income and accessibility of medical care, makes it difficult to conduct further analysis. Moreover, although non-response bias is inevitable in this study, we believe non-response bias does not have large potential influence on our results, as characteristics of the excluded patients are similar to those participating in the study.

\section{Conclusions}

This study showcases that the participation rate of the free medication program among non-registered permanent residents with SMD in Bao'an District, Shenzhen, has increased steadily year by year, from $28.83 \%$ in 2016 to $58.32 \%$ in 2020 . The rising trend indicates that the program has been gradually accepted and recognized by the patients. However, nearly half of the patients have yet to agree to join the program. Further efforts should be made to improve the participation rate of patients who are financially secure, aged below 20, without guardians, suffering intellectually disability with mental disorder, or suffering SMD for over 5 years. Impoverished patients are more inclined to participate in the free medication program, suggesting that the program can indeed help poor families obtain psychiatric medications. According to these findings, this study recommends the following: (1) Efforts should be made to further understand the medication needs of non-registered permanent residents with SMD and the side effects of antipsychotic drugs so as to optimize the free medication program. (2) Doctors with community health centers should regularly follow up the patients and hold lectures on medication to improve the patients' and their families' understanding of medication adherence and the free medication programs.

\section{Abbreviation \\ SMD: Severe mental disorders}

\section{Acknowledgements}

We would like to express our sincere gratitude to Shenzhen Mental Health Center for developing the Shenzhen Information System for Psychosis. We gratefully acknowledged the doctors with community health centers for their regular follow-up visits and services for SMD patients. Our sincere thanks also go to the clinical psychology department of Bao'an District General Hospital for implementing the free medication program as well as the 
staff of the Bao'an Center for Chronic Disease Control for their comprehensive management of the program.

\section{Authors' contributions}

CHL participated in the study design, data collection, data analysis, drafted the manuscript and finalized the manuscript with inputs from all authors. YDL, JC, LQ, QC, CFL were responsible for data collection and project management. JHZ, JLL conducted the data analyses. All authors read and approved the version submitted for publication.

\section{Funding}

This study has been supported by Health and Medical Project for Fundamental Research in Shenzhen (2020JD121) to CHL.

\section{Availability of data and materials}

The datasets used and/or analysed during the current study are available from the corresponding author on reasonable request.

\section{Declarations}

\section{Ethics approval and consent to participate}

All the patients signed the informed consent, among which the patients over 18 years old who lack self-awareness, the patients under 18 years old and the paitents with illiterate signed the informed consent by their guardians. This study involving human participants was in accordance with the ethical guidelines under the Declaration of Helsinki and was approved by the Ethical Review Committee of the Bao'an Center for Chronic Disease Control. Our study followed the Strengthening the Reporting of Observational Studies in Epidemiology (STROBE) reporting guideline. All methods were performed in accordance with the relevant guidelines and regulations.

\section{Consent for publication}

Not applicable.

\section{Competing interests}

The authors declare no conflict of interest.

\section{Author details}

'Shenzhen Bao'an Center for Chronic Disease Control, Shenzhen, China. ${ }^{2}$ Songgang People' Hospital, Bao'an District, Shenzhen, China. ${ }^{3}$ Affiliated Cancer Hospital and Institute of Guangzhou Medical University, Guangzhou, China.

Received: 9 April 2021 Accepted: 17 September 2021

Published online: 30 September 2021

\section{References}

1. Chen HH, Phillips MR, Cheng H, Chen QQ, Chen XD, Fralick D, et al. Mental health law of the People's republic of China (English translation with annotations). Shanghai Arch Psychiatry. 2012;24(6):305-21. https://doi.org/1 0.3969/j.issn.1002-0829.2012.06.001.

2. Xinhua News Agency. The number of patients with severe mental disorders registered in China reached 5.81 million. Available from: http:// www. xinhuanet. com/2018-01/26/c_1122323778.htm. Accessed 12 Aug 2019.

3. Gao ZZ, Cao XY, Zhu JP, Zhu GH, Gao WB, Kong HH, et al. The third epidemiological survey of mental disorders in Weifang (Chinese). Chin J Nerv Ment Dis. 2006;32(2):152-3. https://doi.org/10.3969/j.issn.1002-0152.2 006.02.015.

4. Ulrike S, Neeltje V, Schulze LN, Thea S, Franziska R, Langosch JM, et al. Predictors of medication adherence among patients with severe psychiatric disorders: findings from the baseline assessment of a randomized controlled trial (tecla). BMC Psychiatry. 2018;18(1):155. https://doi.org/10.11 86/s12888-018-1737-4

5. Xu AP, Bu XF, Dong L, Ge MH, Liu PP, Liu WJ. Effect evaluation of the free medication for poor people with serious mental illness in Weifang. Journal of Psychiatry (Chinese). 2013(03):178-180. doi:https://doi.org/10.3969/j.issn.1 009-7201.2013.03.006.

6. Grover S, Avasthi A, Shah S, Lakdawala B, Chakraborty K, Nebhinani N, et al. Indian psychiatric society multicentric study on assessment of health-care needs of patients with severe mental illnesses. Indian J Psychiatry. 2015; 57(2):181-9. https://doi.org/10.4103/0019-5545.158185.
7. Good BJ, Good MJ. Significance of the 686 program for China and for global mental health (Chinese). Shanghai Arch Psychiatry. 2012;24(3):175-7. https://doi.org/10.3969/j.issn.1002-0829.2012.03.008.

8. Dou L, Hu LL, Zhang N, Cutler H, Li SP. Factors associated with medication adherence among patients with severe mental disorders in China: a propensity score matching study. Patient Prefer Adherence. 2020;14:132939. https://doi.org/10.2147/PPA.S255934

9. Liu YB, Li YX, Dai YL, Zhang XM. Analysis on influencing factors of free medication policy for patients with severe mental disorders in Dahongmen area of Beijing (Chinese). Psychol J. 2019;014(013):229,58.

10. Chen Y, Li B, Huang QZ, Zhou XL, Wang XY, Run F. Survey on medication participation status and fiscal investment in patients with severe mental disorder from 2015 to 2017 in Beijing (Chinese). Practical journal of cardiocerebrovascular disease. 2019;27(02):57-61. https://doi.org/10.3969/j.issn.1 008-5971.2019.02.013.

11. Gan YW. Survey on free psychotropic drug use in community patients with mental disease (Chinese). China Medicine and Pharmacy. 2012;2(14):111-2 CNKI:SUN:GYKX.0.2012-14-072.

12. Zhu $Y$, Zhang WB, Wang $W L$ Jiang $Q$, Guo $Y P$, Kang MY, et al. Study on status and countermeasure of free medication for unemployed poor patients with mental disorder in Shanghai City (Chinese). China Medical Herald.2013,10(34): 109-111+114. doi: CNKI:SUN:YYCY.0.201334-040.

13. Zhang T, Xu XH, Li MS, Wang H, Yang JF, Zheng WB. Analysis on the current situation of taking medication and the participation rate of taking free medication among patients with schizophrenia in remote communities in Yunnan Province (Chinese). Chin J Prev Cnotr Chron Dis.2017,25(01):4951.doi: 10.16386/j. cjpccd.issn.1004-6194.2017.01.013.

14. Lu CH, Zhang QS, Zhong JH, Zeng J, Xie Y, Zhu W, et al. Evaluation of the effect of drug fee reduction policy for severe mental disorders in Baoan district, Shenzhen (Chinese). Chronic Pathematology J. 2018,19(08):9991001+1004.doi: CNKI:SUN:YYSO.0.2018-08-004.

15. Xiao G, Lu DQ, Li SX. Curative effects of patients with schizophrenia before and after community free treatment (Chinese). Chinese Journal of Rehabilitation. 2009;24(01):71-2. https://doi.org/10.3870/zgkf.2009.01.039.

16. Ding $X B$, Huang JF. Curative effects analysis of free medication policy for schizophrenic patients in poverty. Medical Journal of Chinese People's Health (Chinese).2013,25(21):8-10.doi: https://doi.org/10.3969/j.issn.1672-03 69.2013.21.004.

17. Li JH, Lu SL, Yu ZY, Zhong H, Chen HZ, Wu JG. Efficacy of free distributing antipsychotics to the schizophrenics: one year follow-up study (Chinese). Shanghai Archives of Psychiatry. 2008(04):213-215. doi: https://doi.org/10.3 969/j.issn.1002-0829.2008.04.007.

18. Hu LL, Wang C, Wang YH. Effect of medication assistance policy on medication compliance of patients with severe mental disorders (Chinese). J Psychiatry. 2018;31(05):376-8. https://doi.org/10.3969/j.issn.2095-9346.2018. 05.015.

19. Zhou Y, Chen SQ, Wu ZM. Effect of social support on rehabilitation of the patients with schizophrenia. (Chinese). Journal of Nursing Science. 2005(19): 4-6. doi: CNKI:SUN:HLXZ.0.2005-19-002.

20. Shenzhen Municipal Bureau of Statistics. Shenzhen Statistical Yearbook 2020. China Statistics Press;2020. Available online: http://www.sz.gov.cn/ cn/ xxgk / zfxxgj/tjsj/tinj/content/post 8386385.html.

21. CCID Consulting Company Limited. White paper on the development of China's top 100 regions 2018. Available online: https://www.sohu.com/ a/ 253975439_818773. Accessed 14 Sept 2018.

22. Gao XP. Countermeasures to the management of floating population in urban community (Chinese). J Liaoning Police College. 2019;21(05):67-71.

23. Yao HS, Xu XJ, Xue DS. Progress of the research on the floating population in China (Chinese). Urban Probl. 2008;6:69-76. https://doi.org/10.3969/j.issn.1 002-2031.2008.06.014.

24. Yuan XM. Empirical analysis on current trait and problems of urban floating population in Shanghai (Chinese). East China Econ Manage. 2008;7:4-8. https://doi.org/10.19629/j.cnki.34-1014/f.2008.07.001.

25. Li RF. On the formation of the dual household registration system in China (Chinese). Xi Nan Ke Ji Univ J. 2007:6:16-9. https://doi.org/10.3969/j.issn.1 672-4860.2007.06.004.

26. Jiang MH, Wang GY. The social integration of rural female floating population with cities - investigations and considerations in Henan Province (Chinese) . Chinese Women's Acad Shandong Col J. 2009:3:22-25. doi: CNKl: SUN: ZHLZ. 0.2009-03-008. 
27. Luo JJ, Jiang GQ, Wang QG. Analysis of medication situation of registered patients with severe mental disorders in Chongqing in 2017 (Chinese). China Pharmaceuticals. 2018;27(23):83-6. https://doi.org/10.3969/j.issn.1006-4 931.2018.23.027.

28. Liu CF, Chen Q, Lu CH. Qing Li, Cheng Juan, fang WJ. Implementation effect of medication subsidy policy for patients with severe mental disorders. Modern Preventive Medicine. 2021;48(04):690-3.

29. Chen Y, Li ZB, Xu QY, Huang QZ, Yan F, Yang Y. The effect of free medication service patterns on serious mental disordered patients and fiscal expenditure. Capital Journal of Public Health. 2016;10(04):186-8. https://doi. org/10.16760/j.cnki.sdggws.2016.04.014.

30. Guo ZJ, Wang YJ, Wang CH, Wang HL, Zhang RL, Yao FJ. A study on influencing factors and current status of drug compliance in patients with serious mental disorder in Henan (Chinese). Chin J Psychiatry. 2020;53(04): 321-7. https://doi.org/10.3760/cma.j.cn113661-20190731-00254.

31. Mi WF, Ma WB, Xiong J, Shi ZQ, Li LZ, Huang L, et al. Compliance with antipsychotic treatment and relapse in schizophrenia (Chinese). Chinese Journal of Psychiatry. 2012;45(1):25-8. https://doi.org/10.3760/cmaj.issn.1 006-7884.2012.01.011.

32. Wang X, Ma N, Wu XM, Guan LL, Guo JH, Zhang WF, et al. Analysis of medication compliance and causation in patients with schizophrenia in community (Chinese). Chin J Nerv Dis. 2016;42(6):374-8. https://doi.org/10.3 969/j.issn.1002-0152.2016.06.012.

33. Wu Y, Fan J, Bao ZH, Guo T, Tang L, Feng W, et al. Investigation on medication compliance of patients with severe mental disorders and its influencing factors in the community of Wuxi (Chinese). Chinese General Practice. 2020;23(04):490-4.

34. He KY, Zhou YQ, Long HW, Li XH, Ou WH. Drug compliance in schizophrenic patients (Chinese). J Clin Psychol Med. 2000;01:9-11. https:// doi.org/10.3969/j.issn.1005-3220.2000.01.003.

35. Meng B, Zhang BK, Zhu WG, Chen MH, Wang YS. Evaluation of drug compliance among schizophrenic patients (Chinese). J Clin Psychiatry. 2009, 19 (02): 102-103. (Chinese). doi: CNKI:SUN: LCJS.0. 2009-02- 017.

\section{Publisher's Note}

Springer Nature remains neutral with regard to jurisdictional claims in published maps and institutional affiliations.

Ready to submit your research? Choose BMC and benefit from:

- fast, convenient online submission

- thorough peer review by experienced researchers in your field

- rapid publication on acceptance

- support for research data, including large and complex data types

- gold Open Access which fosters wider collaboration and increased citations

- maximum visibility for your research: over $100 \mathrm{M}$ website views per year

At $\mathrm{BMC}$, research is always in progress.

Learn more biomedcentral.com/submissions 